\title{
New technical solution for resource-saving tasks in chemical plant protection
}

\author{
Ivan Borisenko ${ }^{1,2 *}$, Marina Meznikova ${ }^{1}$, Omariy Chamurliev ${ }^{1}$, and Ekaterina Ulybina $^{3}$ \\ ${ }^{1}$ Volgograd State Agrarian University, Volgograd, Russia \\ ${ }^{2}$ Caspian Agrarian Federal Scientific Research Centre of Russian Academy of Sciences, v. The Salted \\ Zajmishche, Astrakhan region, Russia \\ ${ }^{3}$ Mikhailovsky College of Technology, Volgograd region, Russia
}

\begin{abstract}
The problems in the production of row crops are considered. The technical solution in the field of chemical protection of plants, aimed at obtaining high quality products while reducing the cost of production, is offered. The retrofitting of serial boom sprayers with special divider bodies makes it possible to retain the function of continuous spraying with the possibility of chemical treatment in strips at the desired phase of growth and development of cultivated plants. It also describes the possibility of solving environmental problems in the agricultural industry by reducing the chemical load on the soil.
\end{abstract}

Countries around the world are currently experiencing difficult times. The coronavirus pandemic has exacerbated economic problems. In the area of production it is even more important to cut costs. Especially sensitive to cost reduction is the agricultural sector, since profits are directly dependent on the sale of the products produced. At the same time, the purchasing power of the population is decreasing. Therefore, the provision of food becomes the main task of any state on the entire planet [1]. In these difficult times, it is important that all the developments of scientists and researchers in various fields became available to the public, and also had the opportunity to be implemented in enterprises of all forms of ownership [2,3]. In the field of crop production, the introduction of new technical solutions aimed at obtaining competitive products of high quality in the required volume with the possibility of reducing costs may be the salvation from the ruin of many farms. Also, we should not forget that the pandemic will end and environmental problems will come to the fore again. In order not to accumulate unresolved problems in the field of environmental protection, at the stage of implementation of new technologies and technical solutions for their implementation, the solution of environmental problems must be put before the developers of such approaches and make them no less important than the profit. This proves the need to change the approach to the implementation of existing crop technologies [4,5].

A team of scientists from Volgograd State Agrarian University has been developing and successfully implementing the technology of strip-tillage of row crops for more than 5 years. The technology is based on solving the problems of producing high-quality products at reasonable cost with care for the environment. The application of strip cultivation

\footnotetext{
* Corresponding author: borisenivan@yandex.ru
} 
technology for row crops in the farms of the Volgograd region has proven its effectiveness in terms of technological, technical, environmental and economic indicators. The implementation of this technology gives the most significant effect when applied to row crops and industrial crops [6]. In addition, it has good prospects for vegetable, melon crops, the cultivation of medicinal herbs and cotton growing [7].

A significant amount of row crops are produced worldwide each year. In Russia, for example, about $23 \%$ of the total cultivated area in 2020 is occupied by crops intended for cultivation in the strip farming system. At the same time, sunflower production accounts for $10.6 \%$ with a steady annual growth due to the increase in demand and prices for this product. This means that the prospects for strip-tillage technology in Russia will expand [810]. The general approaches in strip-till technology are based on the known principles of strip-till technology application, however, they have their own features. For example, the technological process of strip-tillage has been changed, and now it is possible to work deeper (up to $0.4 \mathrm{~m}$ ) without excessive abrasion of valuable soil particles on the surfaces of working tools and reducing the spraying process in the process of tillage. In addition, the problem of increasing the volume of applied chemicals and increasing the cost of chemical treatment of crops was solved. To this end, the technology of strip chemical treatment of row crops and the technical solution for its implementation were developed [6]. According to the patent 2709762 of the Russian Federation, a new method of strip chemical treatment of crops was proposed, which allows to treat only that strip which is necessary. At the same time, the possibility of continuous spraying is preserved (Figure 1).

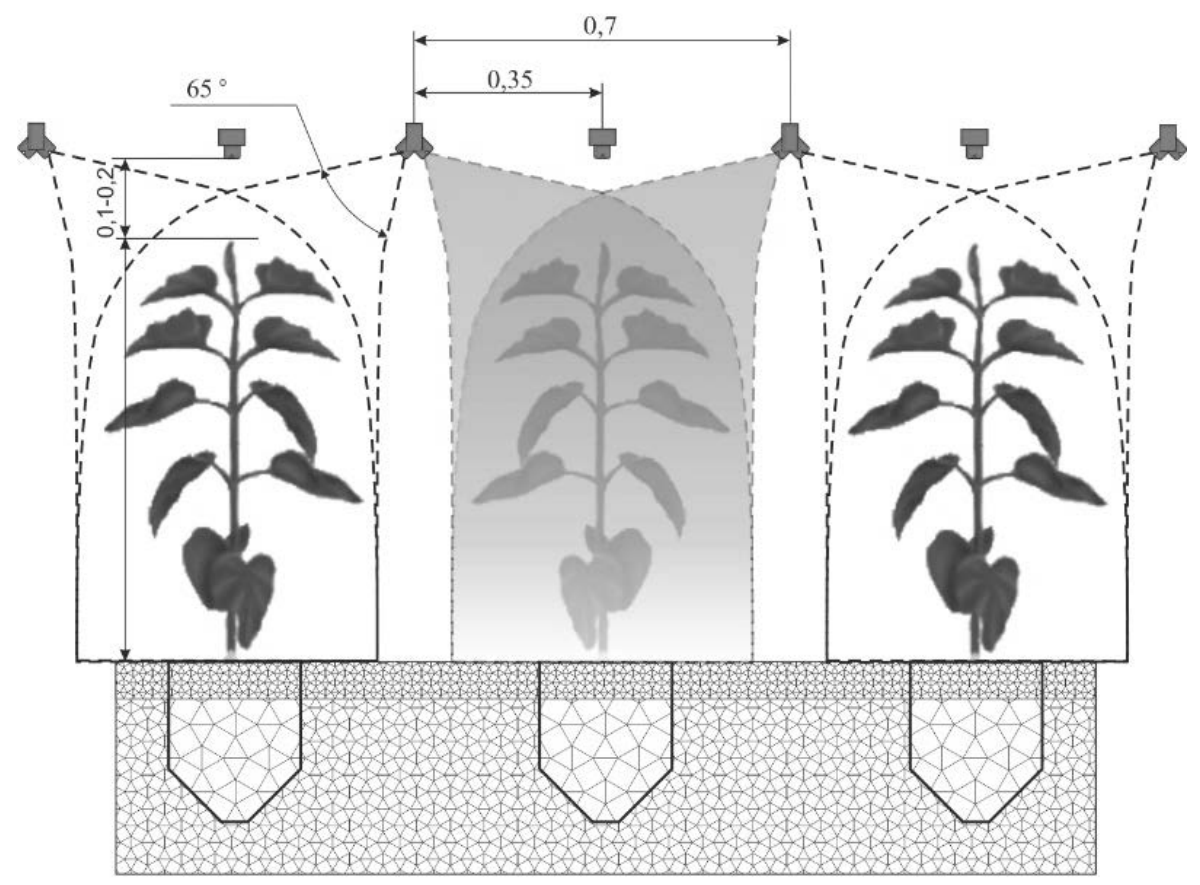

Fig. 1. The fusion of the fluxes of the working solution in the strip chemical treatment.

For this purpose, innovative divider bodies with slotted nozzles are mounted on the sprayer boom. During the spraying operation, the spray liquid flows through the divider 
bodies and a new liquid flow is created by merging two flows from adjacent nozzles. This results in a more stable flow in width and height. The qualitative performance of strip spraying is markedly improved [7]. By transferring a part of the working solution from the soil surface to the object of treatment within the desired band, we achieve a reduction of the chemical load on the soil. This proves the environmental friendliness of the technological process of strip chemical treatment.

This technical solution was tested on the fields of the Volgograd region in July 2019. After performing the technological operation of strip spraying on sunflowers in the phase of 5-6 leaves, the qualitative indicators of spraying were investigated and the environmental prospects of the technology were evaluated.

The results of studying the distribution of the working solution drops on the surface of the leaves by tiers, on the stem and on the backside of the sunflower leaves confirmed the advantages of the new technology of strip chemical treatment compared to the traditional continuous spraying. The density and dispersion composition of the deposited droplets were evaluated.

When spraying according to the traditional technology (with vertical direction of the spraying cone on the soil), 36-40\% of the tank solution got into the interstrip space. On the outer side of the leaves of the plant and along the leaf volume abstract - 60-64\%, with 80$85 \%$ located at $1 / 3$ of the height from the top. There were no drops of working solution on the inside of the leaf and stem.

After a quick readjustment of the serial equipment for band treatment, by installing innovative housing-dividers, performing the merger of streams from side nozzles located at an angle of 450 with the formation of a new single vertical stream, on the soil in the interrow was $17-20 \%$ of the tank solution, and thus on the cultivated plants - $80-83 \%$. Application of the indicator method made it possible to establish that drops on the outer side of the leaves fell on the whole height. Droplets of the working solution were found on the stem of the plant throughout the height and on the inner surface of the leaf.

Thus, the method of evaluating the quality of spraying when using the method of strip chemical treatment of plants on the example of sunflower has shown the advantages of this method in comparison with the continuous spraying, and the installation of innovative divider bodies with spray torches oriented towards each other contributes to a more stable flow and higher quality treatment of crops

Redistribution of working solution flows from the row to the object of treatment allows us to draw a conclusion about the advantages of the new way of applying the preparation to the crop. At the same time the ecological effect increases depending on the width of the row spacing. At the inter-row width of $0.7 \mathrm{~m}$ the environmental friendliness of the technology increases by $20-24 \%$.

When growing vegetable crops using the strip volumetric spraying technology, the sprayer placement changes and the environmental friendliness increases. Figure 2 shows the scheme of tomato planting on drip irrigation.

Thus, with a row spacing of $1.5 \mathrm{~m}$, taking into account the placement of sprayers at 1.5 , 1.1 and $1.0 \mathrm{~m}$, respectively, the uncultivated strip increases from $0.315 \mathrm{~m}$ to 0.66 and 0.75 $\mathrm{m}$. Which corresponds to an increase in the environmental friendliness of the technology by redistributing the impact from the soil to the plant from $21 \%$ to $44 \%$ and $50 \%$. 


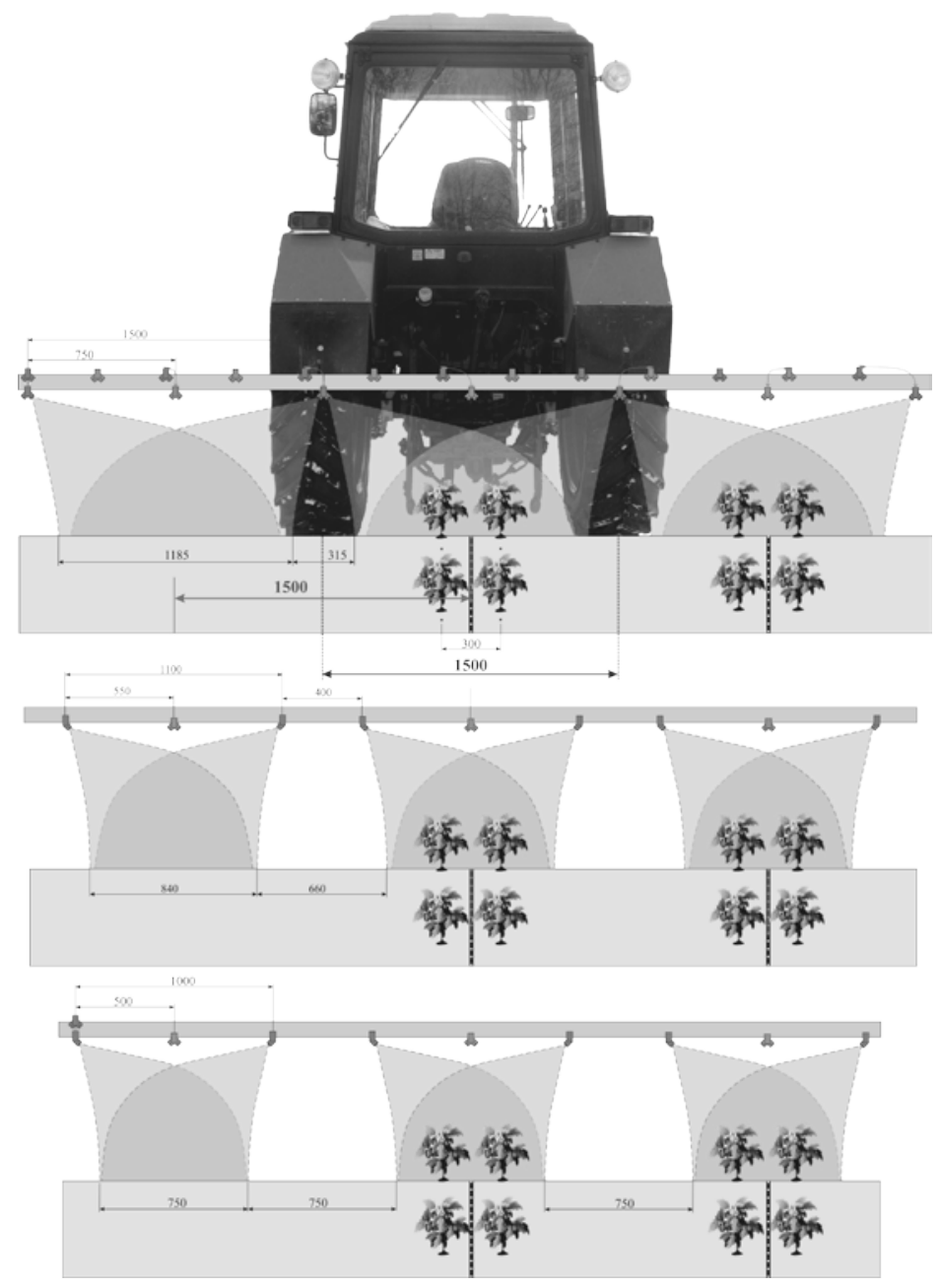

Fig. 2. Flow distribution from the placement of sprayers on the boom.

\section{References}

1. M. Shaprov, P. Borisenko, News of the Nizhnevolzhsky Agrouniversity Complex, 4 (32), 193 (2013)

2. S. Kambulov, V. Rykov, E. Trubilin, Research Journal of Pharmaceutical, Biological and Chemical Sciences, 4, 599 (2018)

3. V. Churzin, A. Dubovchenko, News of the Nizhnevolzhsky Agrouniversity Complex, 3 (59), 181 (2020)

4. E. Canales, J. Bergtold, J.Williams, Agricultural and Resource Economics Review, 47(1), 90 (2018)

5. G. Medvedev, N. Ekaterinicheva, A.Tkachenko, News of the Nizhnevolzhsky Agrouniversity Complex, 3 (59), 116 (2020)

6. I. Borisenko, A. Ovchinnikov, M. Meznikova, S. Fomin, Conference on Innovations in Agricultural and Rural development IOP Conf. 341 (2019)

7. I. Borisenko, M. Meznikova, E. Ulybina, News of the Nizhnevolzhsky Agrouniversity Complex, 4 (60), 340 (2020) 
8. V. Churzin, A. Dubrovchenko, News of the Nizhnevolzhsky Agrouniversity Complex, 1 (57), 158 (2020)

9. I. Jaskulska, L. Gałęzewski, M. Piekarczyk, D. Jaskulski, Italian Journal of Agronomy, 13(3) 194 (2018)

10. S. Shchukin, E. Gornich, A. Trufanov, A. Voronin, News of the Nizhnevolzhsky Agrouniversity Complex, 4 (56) 119 (2019) 